\title{
Comparison of various approaches to design wind-PV rural electrification projects in remote areas of developing countries
}

\author{
Domenech B*, Ferrer-Martí L, Pastor R \\ Industrial Engineering and Logistics Group (EOLI) \\ Universitat Politècnica de Catalunya (UPC), BarcelonaTech \\ Corresponding author $(*)$ : Serra Hunter Fellow; bruno.domenech@upc.edu
}

\begin{abstract}
Nowadays, around 1.1 billion people in rural and remote areas of developing countries remain without electricity. Stand-alone projects that combine the wind and photovoltaic generation technologies as well as microgrids and individual supplies for the distribution network are an adequate strategy to reach such isolated regions. However, the design of electrification projects is complex, having to define the best combination of generation and distribution technologies, under a challenging social context and tight techno-economic resources. In order to ease decision-making, several tools have been developed in the literature and are here reviewed, grouped into three main categories: optimisation processes, aiming to minimise project costs subject to technical constraints, through exact or heuristic algorithms; multicriteria processes, using different methods to select the best among a set of predefined scenarios according to economic, technical, social and environmental criteria; and systematised tools, that have been developed to provide user-friendly interface for their larger dissemination in different regions and contexts. Hence, this paper aims to provide researchers and practitioners an analysis of the advantages and limitations of approaches used over the last decade when addressing the designing of wind and/or photovoltaic electrification projects for extremely poor and isolated areas in developing countries, as well as some areas for further research.
\end{abstract}

\section{Introduction}

In 2015, the United Nations defined the Sustainable Development Goals, the seventh of which is to: "ensure access to affordable, reliable, sustainable and modern energy for all" (UNDP, 2015). In particular, in 2030 each human being in the planet should have between 50 and 100 $\mathrm{kWh} /$ year of electric energy. Indeed, electricity access favours (DFID, 2002; Baldwin et al., 2015): developing productive activities, increasing study hours, accessing new telecommunication technologies, using low polluting cooking and heating technologies, night attention at health centres, refrigerating vaccines and food, etc. In particular, the positive impacts of electricity for remote populations have been highlighted in terms of lower family expenses on traditional energy supply (kerosene, batteries, mobile recharging, etc.), while improving indoor air conditions (Obeng et al., 2008; Aklin et al., 2017). In addition, when appropriately conceived, electricity supply can help to increase family incomes, having more daily hours to study or work, and even for entertainment (Grimm et al., 2014; Karumba and Muchapondwa, 2017). Finally, the increase of women decision-making within families, has also been reported (Samad et al., 2013).

However, nowadays still 1.1 billion people lack of electricity, especially in rural areas of developing countries (IEA, 2017). In order to provide electricity in such regions, most governments extend the national electric grid, but significant technical and economic limitations occur in mountainous and hardly accessible areas with dispersed houses and low end-user demands (Kaundinya et al., 2009; Mahapatra \& Dasappa, 2012; Nygaard \& Dafrallah, 
2016; IEA, 2017). Although grid-connected facilities will still be necessary to reach rural areas, isolated projects will be helpful and cost affordable in poor and low-demand density areas (ESMAP, 2007). In fact, off-grid electrification systems are progressively being deployed; using different technologies for electricity generation and distribution (Mendes et al., 2011; IEA, 2017). In this regard, Mandelli et al. (2016a) distinguish between: stand-alone systems, when a single end-user is supplied by a single energy source; microgrid systems, when several end-users are supplied by a single energy source; and hybrid microgrid systems, when several end-users are supplied with several energy sources.

Regarding electricity generation, diesel generators have been traditionally used, but they create external dependences on fuel and greenhouse gas emissions (Akorede et al., 2010). Renewable technologies can overcome such limitations, improving projects sustainability (Brent \& Rogers, 2010; Yadoo \& Cruickshank, 2012). For instance, micro-hydroelectric power plants can obtain electricity from river falls. This is a widely used technology, much studied in the literature and economically affordable (Sachdev \& Akella, 2015). However, its implementation is directly linked to the availability of nearby rivers with a sufficient flow and fall. Therefore, this paper focusses on less favoured regions not having rivers close, thus having to use alternative technologies based on resources available almost everywhere in the world: the sun and the wind. Solar photovoltaic (PV) has been widely utilised over the last decades, especially as individual-based systems for domestic or productive purposes (Akikur et al., 2013). Some recent reviews about experiences with such technology can be found for Argentina (Díaz et al., 2013), China (Shyu, 2013), Kenya and Tanzania (Ondraczek, 2013), Middle East and North Africa (Tsikalakis et al., 2011), Morroco (Carrasco et al., 2013), South Africa (Lemaire, 2011), South Asia (Palit, 2013) or developing countries globally (Chaurey \& Kandpal, 2010a). Wind energy receives increasing attention, given its high technical and economic performance in windy regions (Kaldellis et al., 2007; Hosseinalizadeh et al., 2017). Experiences with smallscale wind turbines have been reported in Inner Mongolia, China (Zhang et al., 2001), Nicaragua (Leary et al., 2012) and Peru (Ferrer-Martí et al., 2010; Ferrer-Martí et al., 2012). Lastly, hybrid systems, and specifically wind-PV, is a very suitable option since both resources complement to each other, reducing project costs and improving supply reliability (Nema et al., 2009; Zhou et al., 2010; Dufo López et al., 2011; Elma \& Selamogullari, 2012; Kaldellis $\&$ Zafirakis, 2012). Some recent reviews about the increasing use of this technological option can be found in Fadaeenejad et al. (2014), Neves et al. (2014) and Khare et al. (2016).

Regarding electricity distribution, given the dispersion between houses in rural communities of developing countries, many electrification projects consider individual supplies (Ferrer Martí et al., 2010; Domenech et al., 2014): independent electricity generation, storage and distribution for each demand point (houses, health centres, schools, etc.). Alternatively, microgrids simultaneously feeding several demand points have significant advantages (Alzola et al., 2009; Kirubi et al., 2009): the consumption of a point is not limited by its emplacement, equity between users is favoured, costs can be saved through higher opportunities for economies of scale and the consumption flexibility is improved. Thus, microgrids have proven beneficial to provide electricity to isolated communities autonomously (Mendes et al., 2011; Yadoo \& Cruickshank, 2012; Domenech et al., 2014; Pedersen, 2016). In this regard, research 
on remote microgrids has been increasing over the last years (Chaurey \& Kandpal, 2010b; Ustun et al., 2011; Kemausuor \& Ackom, 2017).

As observed, the design of stand-alone electrification projects for remote communities is not straightforward, having to define the generation (wind and/or PV) and distribution (individual supplies and/or microgrids) technologies. In fact, a global rural electrification assessment promoted by the World Bank suggested the need for further developments in the analysis of the location and size of equipment for stand-alone and microgrid systems (ESMAP, 2007). Consequently, support tools to assist project developers in decision-making are highly recommended (Hiremath et al., 2007). In this context, the contribution of this paper is to update the literature regarding the design of such off-grid electrification solutions for remote and very poor populations in developing countries. The purpose is not an extensive literature review, but a general overview about the most relevant approaches used over the last 10 years (2007-2017), in order to bring the problem closer to non-expert readers looking for a global and non-technical perspective. Hence, the contribution of this paper is to provide researchers and practitioners an insight on the advantages and limitations of models and tools used in the literature when addressing the design of wind-PV electrification projects for remote and poor locations. So, in the following section, a problem description is provided to delimit the focus of this paper, identifying three types of design approaches, described in the next sections. First, the better design solution is optimised through mathematical models, aiming to maximise or minimise an objective function subject to some technical constraints. Second, the most balanced design solution is sough through multicriteria decision-making processes, according to technical, economic, social and environmental criteria. Third, systematised tools with user-friendly interfaces to assist project developers in several contexts are reviewed. The last section summarises the most relevant findings regarding the reviewed approaches as well as areas for further research. Finally, the main conclusions are summarised.

\section{Problem definition}

As explained in the introduction, this paper focusses on the design of wind-PV stand-alone electrification systems for remote villages in rural areas of developing countries. When conceiving the electricity distribution, individual supplies are cheaper in communities with dispersed demand points; while microgrids are the best option for villages with concentrated points (Chaurey \& Kandpal, 2010b). However, this work focuses on villages with a medium dispersion, where each demand point can be supplied through an individual supply or a microgrid; which has been a less studied in the literature (Rojas-Zerpa, 2012). Consequently, in addition to the socioeconomic issues, the design of such systems may be technically seen as a complex combinatorial optimisation problem (Notton et al., 2011). On the one hand, all possible generator combinations (wind and/or PV) must be explored in order to satisfy the electricity requirements of population, according to the availability of energy resources. On the other hand, all possible connections between demand points must be explored, balancing microgrids extension (and subsequent benefits) and cost increases when connecting far demand points (Ferrer-Martí et al., 2012; Nygaard \& Dafrallah, 2016). Figure 1 illustrates the problem focussed. On the left image, a traditional system where all demand points are individually 
supplied through wind turbines is represented. Logically, the larger the demand, the larger the generator implemented. On the right image, microgrids are implemented to supply concentrated points, taking advantage of economies of scale, while isolated points are fed through individual supplies. The wind and solar technologies are used according to the resources available at each point.



Figure 1: Comparison of an individual wind system (left) and a combination of wind-PV generators as well as individual supplies and microgrids (right) (adapted from Ferrer-Martí et al., 2011)

This combinatorial optimisation problem becomes even more challenging when including additional equipment for the appropriate functioning of electrification systems. First, wind-PV solutions are generally implemented together with a battery storage to bridge the gap between the electricity production and consumption periods (Li et al., 2013; Singh et al., 2017). Batteries are loaded when there is production but no consumption (usually daily hours), while they supply electricity in non-production periods (usually non-windy nights). Second, inverters transform the direct current (DC) output from batteries into alternating current (AC). Although such devices are not always used to save costs (Gandini \& de Almeida, 2017), they enable endusers to connect a wider range of electrical appliances (Singh et al., 2015). Finally, microgrids can be conceived under different schemes (Soshinskaya et al., 2014; Prakash et al., 2016). The radial configuration, connections in form of a tree and power flowing in one direction from a single generator location, is the technically simplest and cheapest option; being suitable for rural areas. Figure 2 shows the wind-PV-battery systems considered in this paper with distribution as individual supplies or radial microgrids.

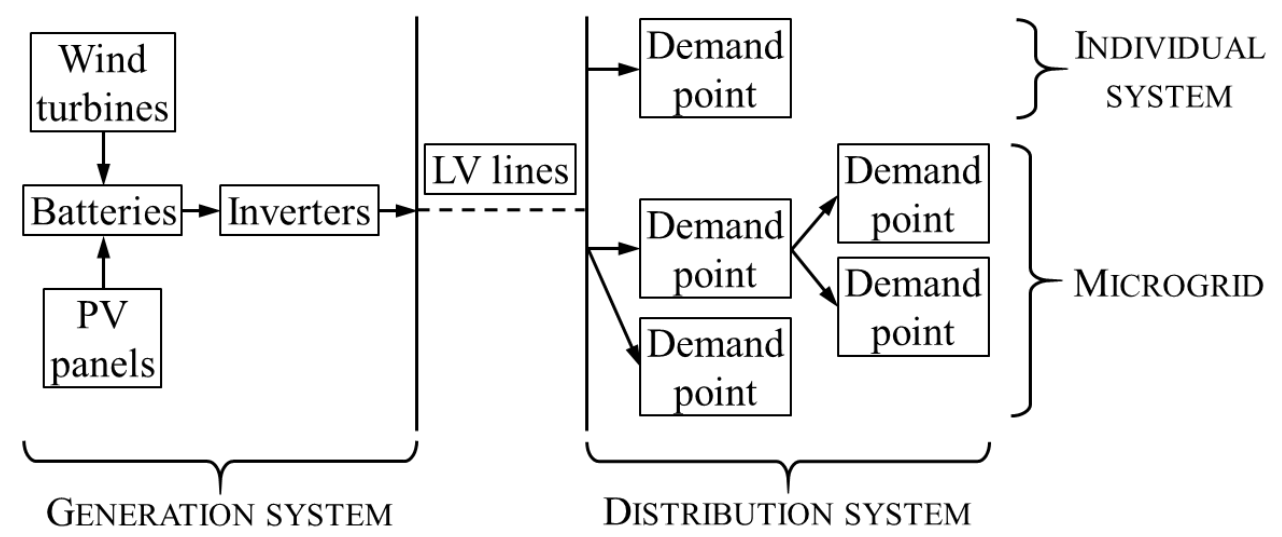

Figure 2: Scheme of a wind-PV-battery electrification system combining electricity distribution as individual supplies or radial microgrids (adapted from Domenech et al., 2015a) 
In addition to the design complexity, the techno-economic resources available for implementing such electrification projects are generally limited. Therefore, standardised solutions are commonly replicated, instead of analysing the best solution for each context, adapted to the needs and characteristics of population (Schäfer et al., 2011; Escobar et al., 2012; Ahlborg \& Hammar, 2014). Consequently, end-users may be disappointed and frustrated in their development expectations, even preferring to return to traditional energy supplies (Lemaire, 2011). Indeed, inappropriate projects may be more detrimental than beneficial, as there is low understanding about how techno-economic issues can properly match social issues (Hong and Abe, 2012). Projects not satisfying end-user expectations might create disbelief in technology, while oversized systems can entail disproportionate costs not balanced by the benefits of electricity access. Moreover, if social aspects are disregarded, users with confronted interests may have to collaborate or unintended inequities in supply might be seen as deliberate, causing conflicts between neighbours. In fact, social issues have been identified as a key issue to ensure projects sustainability at a medium and long term (Müggenburg et al., 2012; Baldwin et al., 2015). Recently, some initiatives aim at involving end-users across the design, operation and maintenance processes to make them active stakeholders instead of passive beneficiaries of a service (Ubilla et al., 2014; Lillo et al., 2015b). Gómez-García \& Bartolomé (2010) propose to change the concept adjusting the technical design of electrification systems to the social requirements.

As observed, the design of wind-PV-battery stand-alone electrification systems for rural villages of developing countries, combining microgrids and individual supplies, is a challenging multifaceted problem (Zhou et al., 2010). Support tools must be user-friendly in order to assist project developers under complex social framework and tight budgets. Evaluations must be performed based on issues such as: energy poverty, demand requirements, energy resources, lifecycle cost-benefit, affordability and sustainability (Zhou et al., 2010; Shrestha \& Acharya, 2015). In the following sections, different approaches for the design of such systems are reviewed.

\footnotetext{
Sidebar title: The complex design of electrification projects in a rural context

The design of stand-alone electrification projects for rural-poor communities in developing countries may be seen as a complex combinatorial optimisation problem. On the one hand, all possible generator (wind-photovoltaic) combinations must be explored in order to satisfy the electricity requirements of population, according to the availability of energy resources at the region. On the other hand, all possible connections between demand points must be explored, balancing microgrids extension (to increase the benefits of such configurations: higher development opportunities, equity in consumption, etc.) and techno-economic issues (costs increases and large voltage drops when connecting demand points too far from each other). In addition, social aspects must be taken into account in order to ensure the project satisfies the real needs and expectations of population, as well as the community feels owner of the project to ensure its appropriate operation and maintenance along the project lifetime. All this activity is generally performed by local governments and NGOs, under limited technical resources and tight budgets. Therefore, the implementation of electrification projects becomes a challenging task, being the technical design subject to the social constraints and issues.
} 
Bhattacharyya (2012) distinguishes five methodological approaches: worksheet-based, optimisation, multicriteria, system-based participatory and hybrid approaches. This paper focusses on optimisation and multicriteria processes, which have the higher interest for researchers and practitioners on rural electrification. Optimisation models seek to define the solution that maximise or minimise an objective function, subject to some constraints or limitations in the solution value. Multicriteria methods pretend to find a balanced solution, according to a set of criteria that better represents the problem preferences. Although both approaches aim to find the best solution, each one uses a different strategy. Optimisation can be seen as a box where some input data is introduced and, though a mathematical process, the best solution is obtained. Consequently, the quality of the solution is directly linked to the quality of the input information. On their behalf, multicriteria methods require from a higher involvement of the decision-maker, to define and adjust decisions according to his/her preferences. As a result, a unique solution is not generally sought but some recommendations about the best set of solutions. In the following sections, first optimisation and then multicriteria processes used to design wind-PV systems for remote locations are reviewed. Although the scope of this paper is projects design, some articles going beyond are also included, particularly for multicriteria. In fact, optimisation models can reach detailed electrification solutions sizing and locating the equipment to be implemented. In contrast, multicriteria tools assist decision-makers in selecting among predefined solutions. Consequently, while optimisation has been widely used to size wind-PV facilities, multicriteria has been utilised for such a purpose (for instance, to select the location for wind turbines (Cavallaro \& Ciraolo, 2005)), but also for project planning (for instance, to decide among gridconnected, microgrid and individual supplies (Rahman et al., 2013)). Note that both approaches are generally not substitutes to each other, but may be complementary (Alarcón-Rodríguez et al., 2010; Bhattacharyya, 2012). Finally, an additional section focussing on systematised tools is included in this paper. Such tools are internally based on optimisation, multicriteria or both processes, but have been distinguished since they provide user-friendly interfaces to be used by researchers and practitioners in several contexts and countries. Such tools do not consider the specific details of each case study, but use general decision-making processes that can be used for very dissimilar communities.

\section{Optimisation processes}

Alarcón-Rodríguez et al. (2010) recommend seeking a balance between the model reliability regarding reality and the quality of the resolution process. A too simplified model and a very detailed resolution process will lead to "a real-solution to a non-problem"; while a very detailed model and a too simplified resolution process will lead to "a non-solution to a real-problem". In this regard, Jebaraj \& Iniyan (2006) state that energy models can support decision-making close to reality, although it is still necessary to pursue research regarding supply security, equipment location and social acceptance (Alvial-Palavicino et al., 2011). In addition, energy models must include an assessment of demand and generation, as well as an analysis of the social impacts of electrification projects at a local scale, analysing the optimal combination of technologies at a short and medium term (Hiremath et al., 2007). 
The development of exact algorithms to solve different problems is currently a dynamic research area obtaining significant improvements in calculation times (Fomin \& Kratsch, 2010). In particular, Atamtürk \& Savelsbergh (2005) state that linear programming is gaining attention as a computational tool to provide optimal or near-optimal solutions for strategic and operational optimisation problems. As indicate Baños et al. (2011), nowadays problems that a few years ago were though unsolvable can be solved thanks to new hardware developments.

\subsection{Combination of energy resources}

The main scope of research when looking at optimisation models for the design of renewable energy-based electrification systems in isolated poor areas is the analysis of a combination of energy sources in order to supply the demand (Zhou et al., 2010; Baños et al., 2011; Bhattacharyya, 2012). Generally, the energy resources and the demand are studied, although the deepness of each work depends on the publication and consequently exact or heuristic procedures have been used to solve the models.

Urban et al. (2007) identify and compile the characteristics of developing countries in order to evaluate whether 12 tools, commonly used in industrialised countries to assist decision-making when planning the future of energy systems, are suitable when applied to such a new context. As a result, the authors conclude about the need to develop specifically-oriented models to address the particular issues of the developing world. In this regard, Ashok (2007) develop an iterative algorithm to design the electrification system of a rural community in India, including the wind, solar and hydro technologies. To do so, all possible combinations of technologies are examined, minimising costs, while using diesel generators and battery storage as a backup to ensure supply continuity. Zamani \& Riahy (2008) develop an optimal sizing method putting special attention on the wind resource. To do so, the instantaneous wind speed variations are analysed for a specific site and the system generation and storage capacity are accordingly sized. Ekren \& Ekren (2009) propose a simulation model to optimise the design of a hybrid wind-PV system with battery storage to cover the demand of a university campus in Turkey. A detailed analysis of energy resources is included, as well as several demand profiles; using diesel generators to improve the system robustness. Saheb-Koussa et al. (2009) perform a techno-economic analysis of hybrid systems in six different sites of rural Algeria, considering typical demand profiles at such regions. The sizing model, developed in Matlab/Simuink v6.5, aims to minimise the cost of energy while ensuring the system self-sufficiency. Kanase-Patil et al. (2010) develop a linear programming model that consider a wide set of energy supply sources in order to define the optimal combination that better meets the expected demand at a minimum cost. The model is solved using Lingo to design an isolated project for 7 villages in Uttarakhand (India).

Gupta et al. (2011) develop a mathematical model to design the most appropriate power supply for a cluster of villages in rural and remote areas of India. In this regard all the equipment components are modelled, aiming to minimise the cost function subject to the satisfaction of the energy and power demand requirements. The model allows considering several generation technologies as well as a battery storage system. Khatib et al. (2012) develop an iterative- 
genetic algorithm to design a PV-wind microgrid for Kuala Terenggan (Malaysia), balancing the project cost and loss of load probability. The optimisation process is organised in three steps: the PV array tilt angle, the energy sources and the inverters size. Mostofi \& Shayeghi (2012) propose an optimisation model that minimises the net present cost of wind-PV-hydro projects with hydrogen storage, applying results to a 12-village area in Blue Qarahsou (Iran). Given the problem complexity, a genetic algorithm, executed in MATLAB, is developed for the model resolution. Trazouei et al. (2013) develop and compare three approaches based on the imperialist competitive algorithm, particle swarm optimization and ant colony, to optimally design a stand-alone wind-PV-diesel system in Iran. The objective is to minimise the project cost, including constraints linked to supply reliability and loss of power probability. Results show the imperialist competitive algorithm to be faster and more accurate this paper. Belouda et al. (2013) propose an integrated optimal design of wind-battery systems in order to size the system capacity satisfying the demand at a minimum cost of ownership. Bogno et al. (2015) evaluate the supply of a school in sub-equatorial Africa by analysing a wind-PV-storage system. Progressive combinations of wind-PV generators are analysed until reaching the minimum cost of the storage system. Chauhan \& Saini (2016) propose a method to integrate several technologies for the supply of a village cluster in India. In order to size the system, an operation strategy is proposed to minimise the loss of power supply probability, ensuring continuity of supply. The project cost of several technological options is minimised using the discrete harmony search algorithm. Mandelli et al. (2016b) present a sizing methodology for off-grid electrification projects, trying to adapt results to the local requirements by optimising the levelised cost of supply and lost energy. Results are applied to a rural community in Uganda.

\subsection{Design of microgrids}

As observed, the works focussing on the combination of energy resources size and, in some cases, located the generation system. However, the way as electricity is distributed to end-users is not defined. Alternatively, the design of microgrids has been studied from different perspectives, including a high technical detail, but has been less investigated within the context of developing countries (Ponce de Leao \& Matos, 1999). The design and location of one or several microgrids has been modelled by different authors using mathematical models. For instance, Wall et al. (1979) consider several microgrids, Gonen \& Foote (1981) select the line to be used according to linearised losses, Aoki et al. (1990) include losses as operation costs and Turkay (1998) includes, in addition, the detail of fixed and variable costs. Finally, Paciornik et al. (2003) change the radial scheme generally used for microgrids in developing countries into a ring scheme in order to improve supply reliability. On their behalf, Ponce de Leao \& Matos (1999) present a method based on simulated annealing to design microgrids, taking into account several decision variables and finding non-dominated solutions. As objective, the investment, operation and maintenance costs are minimised as well as unmet demand, considering the solution robustness and supply security. However, social and environmental aspects are not considered; while they are particularly relevant in rural areas of developing countries. Finally, some authors have compared the socio-technical performance of 
individual supplies and microgrids, although without analysing the detailed design of microgrids (Chaurey \& Kandpal, 2010b; Nygaard \& Dafrallah, 2016).

Very few works specifically address the design of stand-alone electrification projects combining the use of microgrids and individual supplies, despite its usefulness in rural areas of developing countries (Rojas-Zerpa, 2012; Domenech et al., 2014). Ter-Gazarian \& Kagan (1992) develop a linear programming model that simultaneously includes the detail of the energy and power demand, select the line option according to voltage drops and considers conventional and renewable technologies as well as a storage system. As a result, the minimum cost size and location of generation and storage equipment is defined, as well as the microgrid distribution scheme. However, a single microgrid is considered without including individual supplies. In addition, the microgrid structure is a ring, which is very expensive to be considered as a possibility in many rural poor areas.

Lastly, Ferrer-Martí et al. (2011) develop a linear programming model to design stand-alone wind systems, considering the detail of the wind resource, the energy and power demand at each consumption point and the battery storage. As a result, the location and size of equipment is obtained and the model has been used in real projects of the Andean highlands in Peru (Ferrer Martí et al., 2012). Later, Ferrer-Martí et al. (2013) included the PV technology as a combination of wind energy, thus improving supply reliability of obtained solutions. Within this same research, complementary approaches and developments have been proposed. First, Triadó-Aymerich et al. (2016) develop a heuristic method based on relaxations on the mathematical model from Ferrer-Martí et al. (2013) in order to accelerate the resolution speed. Second, Ranaboldo et al. (2015b) seek for a different perspective, using the Greedy Randomised Adaptive Search Procedure, GRASP, meta-heuristic algorithm to achieve better solutions in a shorter calculation time. GRASP is typically used to solve combinatorial optimization problems by iteratively constructing a randomized solution and improving it through a local search. In addition to demand points, this new algorithm allows considering non-demand points as possible locations for generators in order to take advantage of, for example, the wind potential at nearby mountain peaks. The results have been applied to communities in Cape Verde (Ranaboldo et al., 2014a) and Nicaragua (Ranaboldo et al., 2015a). Finally, from an analysis of real electrification projects, Domenech et al. (2015a) include social constraints, identified from the analysis of real projects, in the mathematical model from FerrerMartí et al. (2013) in order to ease the management of the electrification systems and to improve the adequacy of equipment used to end-users.

\section{Multicriteria processes}

Electrification of rural areas in developing countries is a complex task, requiring not only techno-economic aspects, but also social ones (Lillo et al., 2015a). In this regard, taking into account the multiple criteria nature of the problem is a key issue to ensure the community appropriation of the project and, thus, favour its sustainability at a medium and long term (Pohekar \& Ramachandran, 2004; Karger \& Hennings, 2009). Multicriteria methods can assist decision-making to compare different electrification options, minimising the need for arbitrary 
and subjective decisions (Pohekar \& Ramachandran, 2004; Alarcón-Rodríguez et al., 2010; Rojas-Zerpa \& Yusta, 2015). For this process, Wang et al. (2009) propose a general 4-step structure to be followed in any decision process when comparing a set of different alternatives under several criteria: criteria definition, criteria weighting, alternatives evaluation and aggregation of results. In this section, first the criteria definition and weighting are described as most papers simultaneously focus on both aspects. Then, the alternatives evaluation and the aggregation of results are analysed, as the aggregation is commonly used as an extension or sensitivity analysis of the evaluation results.

\subsection{Criteria definition and weighting}

The definition of criteria consists in identifying the relevant criteria to take a decision regarding the design of electrification systems according to the local characteristics (Wang et al., 2009). Generally, criteria are grouped into economical, technical, social and environmental; although some variations in the categories can be found, such as the socioeconomic and institutional (Georgopoulou et al., 1997), the resources (Afgan et al., 2000), the financial (Biswas et al., 2001) or the techno-economic (Cavallaro \& Ciraolo, 2005). Most of the variations are due to the different context, region or scale where the analysis is focussed. Hence, in large-scale works social criteria tend to have an economic implication as job creation (Cavallaro \& Ciraolo, 2005; Karger \& Hennings, 2009). In contrast, in rural areas of developing countries such criteria must be reconsidered (Ostergaard, 2009). For example, in electrified regions aiming to improve the energy supply, aspects such as the noise, greenhouse gas emissions or energy efficiency may be a key issue. However, in non-electrified areas with a limited budget, those criteria are less relevant, since the aim is to provide electricity access to the population; while the supply security becomes particularly relevant (Chatzimouratidis \& Pilavachi, 2009; Wang et al., 2009). However, aspects as the management of electrification system have not been studied in the literature by comparing different electricity distribution structures, which is a key issue for projects sustainability. Nevertheless, when defining evaluation criteria, they must be (Georgopoulou et al., 1997; Afgan et al., 2000): enough to include the opinion of all stakeholders; not too many as to difficult reaching consensus; and measurable and significantly different between them to avoid redundancies and enable a clear and concise analysis.

In the criteria weighting, a value is assigned to each criterion, representing its importance regarding the others (Wang et al., 2009). When working with several criteria simultaneously, the process may not be easy, so several techniques and tools exist to ease decision-making. In this regard, Wang et al. (2009) distinguish between: direct assignment and pair-wise comparison methods. Techniques within the first category have a high subjectivity but are simple to use. An example is the SMART, Simple Multi-Attribute Ranking Technique (Edwards, 1977). Methods within the second category aim to minimise subjectivity by reducing typical inconsistencies from direct assignment. Probably, the most common method is the Analytic Hierarchy Process, AHP, which allows quantifying the consistency of decisionmakers to validate the weighting of criteria (Saaty, 1980). More complex weighting methods have also been developed in the literature, some of them under a mathematical approach, 
although from a research point of view; while their usefulness for energy planning, and particularly rural areas of developing countries, still has to be studied (Wang, et al., 2009).

\subsection{Alternatives evaluation and results aggregation}

The evaluation of alternatives consists in assessing each scenario or electrification option according to each defined criterion (Wang et al., 2009). This is the most complex step in decision-making and many methods have been used and developed in energy planning (Zhou et al., 2006; Loken, 2007; Wang et al., 2009; Alarcón-Rodríguez, 2010). Even the definition of the technique to be used is a multicriteria problem itself (Polatidis et al., 2006). The methods can be distinguished according to whether they are continuous or discrete. The first group have a higher mathematical approach and can be even seen as heuristics optimisation algorithms, but their complexity is significantly higher and can lead to unfeasible solutions. The second group limits the range of possible solutions, and have been more used in developing countries (Polatidis et al., 2006). The following classification of techniques was proposed in Loken (2007) and Polatidis et al. (2006), and can help to understand the nature of different multicriteria approaches in order to select the best technique for each problem:

- Value measurement models. A value is assigned to each alternative, ranking them accordingly (Loken, 2007). Some methods included are the Multi-Attribute Value Theory, MAVT, Multi-Attribute Utility Theory, MAUT (Keeney \& Raiffa, 1976), and Analytic Hierarchy Process, AHP (Saaty, 1980). The first two approaches define a value/utility function for each criterion, which is used to classify the alternatives. AHP is based on pair-wise comparisons, evaluated through a pre-defined scale, to calculate a value representing the suitability of each alternative. These methods are easy to use, transparent and interactive, so have been commonly used in the reviewed literature. However, their use for energy planning is progressively decreasing given the amount of precise information (without uncertainties) they require (Pohekar \& Ramachandran, 2004; Polatidis et al., 2006; Zhou et al., 2006). Therefore, in areas where access to information is not easy they have limitations.

- Outranking models. The alternatives are pair-wise compared regarding each criterion, accepting some uncertainty thresholds, classifying them accordingly (Loken, 2007). Some methods commonly used are Elimination and Choice Expressing Reality, ELECTRE (Roy \& Vincke, 1981), and Preference Ranking Organisation Method for Enrichment of Evaluations, PROMETHEE (Brans et al., 1986). ELECTRE selects a preferred set of alternatives, assuming that alternative A outranks B, if $\mathrm{A}$ is preferred to $\mathrm{B}$ in a minimum amount for some criteria, while $\mathrm{B}$ is preferred to $\mathrm{A}$ in a maximum amount for other criteria. PROMETHEE calculated a global preference index, through pair-wise comparisons between alternatives regarding each criterion, ranking them accordingly. These methods are progressively used as they avoid compensations; i.e. they do not allow a very negative value in a criterion to be balanced by a very high value in another one (Polatidis et al., 2006; Zhou et al., 2006). Generally, they are used is to distinguish most acceptable alternatives among a large set of options (Greening \& Bernow, 2004). However, the concept of threshold is not always clear and may be seen 
as black boxes where decision-makers do not interact across the internal process (Loken, 2007).

- Goal, aspiration and reference level models. The alternatives are compared to an ideal solution (the best for all criteria) and classified accordingly (Loken, 2007). Some methods included are goal programming and compromise programming (Romero, 1993). For instance, compromise programming utilises the mathematical concept of distance to classify the alternatives according to their closeness to the ideal solution. These methods are easy-to-use and understand, are less subjective than value measurement models and enable interaction with decision-maker (Loken, 2007). In particular, compromise programming can achieve results shortly when the amount of criteria is limited and has been used recently (Romero, 1993). For example, Cherni et al. (2007) use the technique to define energy systems for remote regions according to 5 criteria, as described later in this paper. An extension of the compromise programming is TOPSIS, which includes the concept of anti-ideal solution (the worst for all criteria), using it to analyse the expansion of electrical capacity generation (Yang \& Chen, 1989). VIKOR schematises the decision-making process and has been used for the selection of renewable energy options (San Cristóbal, 2011).

Finally, different literature works recommend performing decision-making under an iterative procedure, in order to progressively know part of results while progressing into the analysis, thus easing consensus and improving decisions robustness (Romero, 1993; Greening \& Bernow, 2004). Complementarily, several methods can be used for the same decision process; but the same method used by different decision-makers or different methods used by the same decision-maker can lead to diverse results (Greening \& Bernow, 2004; Polatidis et al., 2006; Loken, 2007; Browne et al., 2010). This fact, widely reported in the literature, is caused by the uncertainty and subjectivity nature of multicriteria decision-making. For instance, having to decide about the weight of a criterion may not be straightforward, and decision-makers might maybe have an idea about a qualitative assessment (very important, important or not important) but quantifying such decision is probably not exact. Therefore, the aggregation of results consists in using different multicriteria methods for a specific decision process, and then converge results through voting or mathematical techniques (Eppel, 1992; Klamler, 2005; Chatzimouratidis \& Pilavachi, 2009; Wang et al., 2009). As an example, Rahman et al. (2013) develop a technique based on Stochastic Multicriteria Acceptability Analysis (SMAA-2) to evaluate several technologies for off-grid electrification, which considers probability distributions for the uncertain decisions as weighting or evaluating criteria. However, the usefulness of the aggregation of results in rural areas of developing countries is limited and no references have about found in that regard. Alternatively, different works do not provide a final solution as a result of the multicriteria decision process, but a set of recommendations or approximate rankings about the scenarios analysed (Georgopoulou et al., 1997).

\section{Systematised tools}

An interesting review of 68 software tools for renewable resources integration in energy systems can be found in Connolly et al. (2010). Moreover, Sinha \& Chandel (2014) compare 
19 software tools for the design of hybrid energy systems. In addition, GIZ (2016) reviews software tools used to assist in the design of electrification projects from a wider perspective, organising them into six groups according to their relation with: rural electrification planning and mapping, resources assessment, technical system design and analysis, financial planning / business model development, operations and management, and others. In fact, a large amount of tools has been developed aiming to respond to the specific needs of each studied area. However, here only the most relevant tools specifically regarding the design of electrification projects in rural areas are described.

Probably, the most commonly used tool worldwide is HOMER, developed by the National Renewable Energy Laboratory, NREL (Akikur et al., 2013). Even specific reviews only focussing on the application of the HOMER tool can be found (Bahramara et al., 2016). This software technically and economically optimises the design of the generation system that better satisfies a specific electricity demand requirement. To do so, a large amount of technologies is considered, including stand-alone conventional (diesel generators) and renewable (solar, wind, micro-hydro, biomass) sources, a battery storage and grid-connection. In addition, a high detail in the demand requirements and the energy resources can be taken into account, as well as uncertainty in parameters such as technology costs. As a result, technically, the number and size of equipment needed is obtained; while, economically, from an estimation of lifecycle (investment, substitution, operation and maintenance) costs, comparisons can be made between different technological options. Moreover, other technical issues such as the yearly electricity production, the excess energy supplied, the demand covered using renewables, etc. are also studied. Some recent examples about the use of HOMER to specifically design wind-PVbattery systems in developing countries can be found in: Bangladesh (Nandi \& Ghosh, 2010), India (Lal et al., 2011), Bhutan (Dorji et al., 2012) Ethiopia (Bekele \& Tadesse, 2012), China (Li et al., 2013), Nigeria (Olatomiwa et al., 2015), Iran (Gheiratmand et al., 2016) and Southern India (Singh et al., 2017). Figure 3 shows an example of a wind-PV-battery system modelled using HOMER to supply a set of houses and a school. Both generators and the battery are connected to a DC bus linked to the $\mathrm{AC}$ bus, from where the loads are supplied, through a converter.

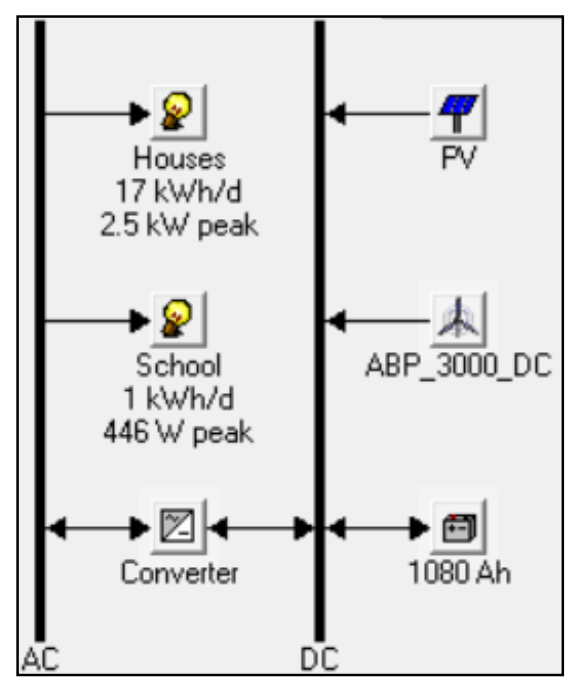

Figure 3: Example of a wind-PV-battery system modelled using HOMER software 
Similar tools to HOMER exist including other issues in the analysis of electrification systems. For example, iHOGA, developed by the Zaragoza University, which is a simulation and optimisation model that, in addition to minimise the project cost along the lifecycle, minimises greenhouse gas emissions and unmet demand (Dufo-López \& Bernal-Agustín, 2011). For the particular case of wind-PV-battery systems, iHOGA has been used in Bangladesh (Bala \& Siddique, 2009), Malaysia (Fadaeenejad et al., 2014) and Libya (Alkarrami et al., 2016). Zubi et al. (2016) analyse general scenarios to supply basic electrical needs of developing regions in the future years using iHOGA, although considering PV-battery systems. HYBRID2, developed by NREL, is a dynamic simulation model that studies the behaviour of different energy systems across their lifecycle, according to several demand profiles (Manwell et al., 2006). The software provides economical information concerning the initial investment of stand-alone electrification projects as well as the operation, maintenance and substitutions costs of equipment (wind turbines, PV panels, diesel generators, batteries inverters), cash flows, the payback period, etc. No recent references have been found on the design of wind-PV-battery systems, while a few years ago examples about the use of HYBRID2 can be found in China (Barley et al., 1997) and Tibet (Honghua et al., 1998).

Regarding the electrical network, ViPOR, also developed by NREL, is an optimisation software that allows designing the distribution system for a community (Lambert \& Hittle, 2000; Williams \& Maher, 2008). From a map of the target area (in order to include terrain complexity), the location of demand points and their electricity requirements, and the costs (investment, operation and maintenance) of equipment, ViPOR evaluates the electrification of each point through a microgrid or individual supplies. To do so, the simulated annealing algorithm is used to minimise costs in two phases: first the low voltage network is conceived, identifying the consumption points to be electrified through the microgrid or individually; and then the medium voltage network is designed, determining the location for transformers and the generation system. Applications of ViPOR for the analysis and design of electrification projects in remote areas can be found in Ghana (Nässen et al., 2002), India (Kumar \& Banerjee, 2010; Rout \& Parida, 2013) and Peru (Ranaboldo et al., 2014b). Figure 4 shows an example of solution obtained for a fictitious community using ViPOR. The solution defines the minimum cost location for generators, among a set of possible locations, the microgrid structure through medium (MV) and low (LV) voltage lines from generators to demand points (houses and community infrastructures) and the individual supplies.

An interesting advantage of the HOMER and ViPOR software is that they can be used together (Mendes et al., 2011). HOMER designs the generation system, combining several technologies, while ViPOR defines the electrical network scheme, combining microgrids and individual supplies. Thus, a comprehensive tool is achieved to entirely design electrification projects. However, ViPOR still has some limitations in the network design (voltage drops are not considered), the solving process of both tools is based on non-exact heuristic algorithms, that can overstate results (Abdul-Salam \& Phimister, 2016), and the use of two tools may not be easy for decision-makers and require several iterations to attain adequate results. In addition, both software focus on an economic and technical analysis, without considering social issues 
that have proven to be a key issue to ensure projects' success in rural areas of developing countries (Ostergaard, 2009; Gómez-García \& Bartolomé, 2010; Müggenburg et al., 2012).

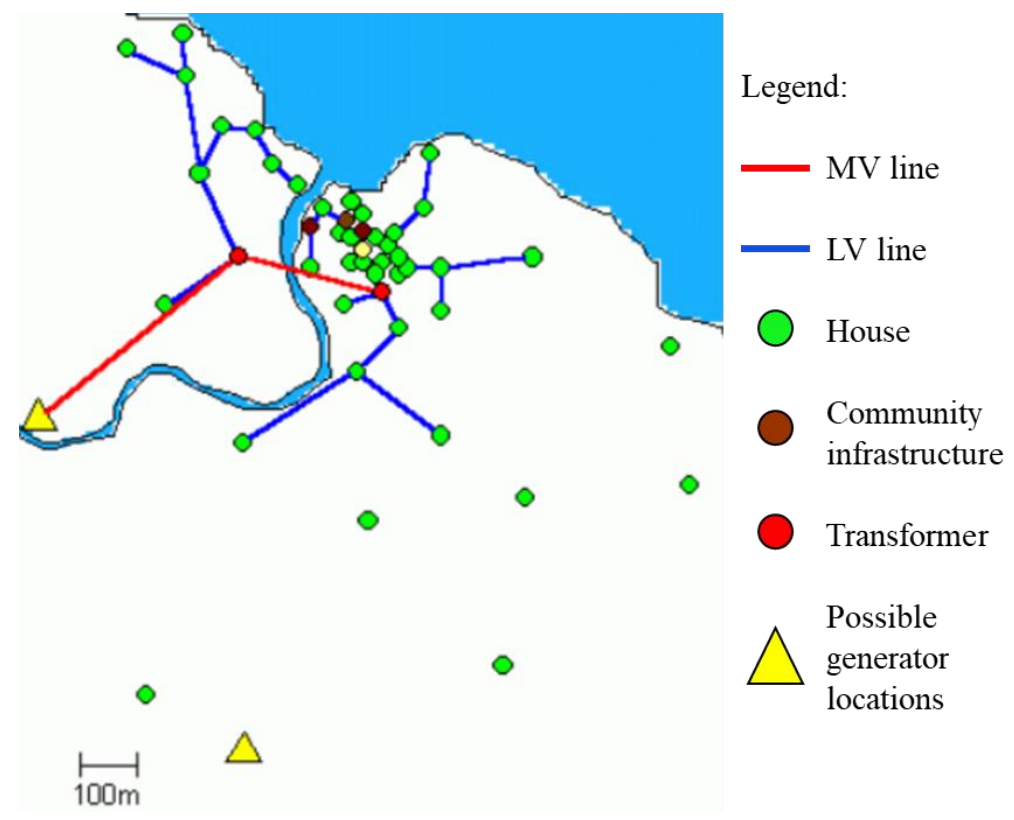

Figure 4: Solution combining a microgrid and individual supplies for a fictitious community, using ViPOR

An additional utility of the HOMER software is the sensitivity analysis to study the influence of some input parameters on the solutions. Applications for wind-PV-battery systems can be found in Bangladesh (Nandi \& Ghosh, 2010) or Kenya (Lukuyu \& Cardell, 2014), among others. In fact, it has been demonstrated that uncertainties in the estimation of the load profile and the energy resources can have a significant impact on the obtained results (Mandelli et al., 2016c). In this regard, an interesting software for the robust design of stand-alone electrification systems has been recently developed (Brivio et al., 2017). The tool called Poli. NRG is structure in four phases: (a) input data gathering concerning weather conditions and demand; (b) inputs processing to determine the load and energy resources profiles over the project lifetime; (c) modelling and simulation of several electrification solutions evaluating the techno-economic performance; and (d) output formulation of the most robust design through an optimisation process. Therefore, a comprehensive tool is achieved to design suitable electrification projects according to the characteristics of each context.

Up to there, the reviewed software tools are based on optimisation processes for the design of off-grid solutions. Under a different approach, SURE-DSS, developed within the Renewable Energy for Sustainable Rural Livelihoods (RESURL) project, uses compromise programming to assess the impact of different technology options on a studied village, according to physical, financial, natural, social and human criteria (Cherni et al., 2007; Henao et al., 2012). This tool is specifically developed for developing countries and starts from a predefined interview to gather information about the population characteristics. With this information, the software calculates the demand requirements, including domestic and community uses, as well as the available energy resources at the area. Then, different technological options are defined and 
evaluated according to their impact on the five criteria. The software user can next define the relevance of each criterion in order to get the best technical option. However, only a general definition of solutions is provided, without detailing the electrical distribution network. In addition, as a decision support system (DSS), it provides information without allowing the software user to interact along the decision-making; which can be a limitation in areas where transparency and clarity in decision is particularly fundamental to ensure end-users satisfaction. Applications of the SURE-DSS can be found in South Africa (Brent \& Kruger, 2009), Colombia (Henao et al., 2012) and Cuba (Cherni et al., 2016). On their behalf, Colombo et al. (2018) propose a comprehensive framework extending SURE-DSS to measure the impact of an energy development project in the livelihood of local population in Ethiopia. Figure 5 shows an example of application of the SURE-DSS tool to a real community in Colombia realised in Henao et al. (2012). The output quantifies how good each studied technology is for the village, according to five different criteria.

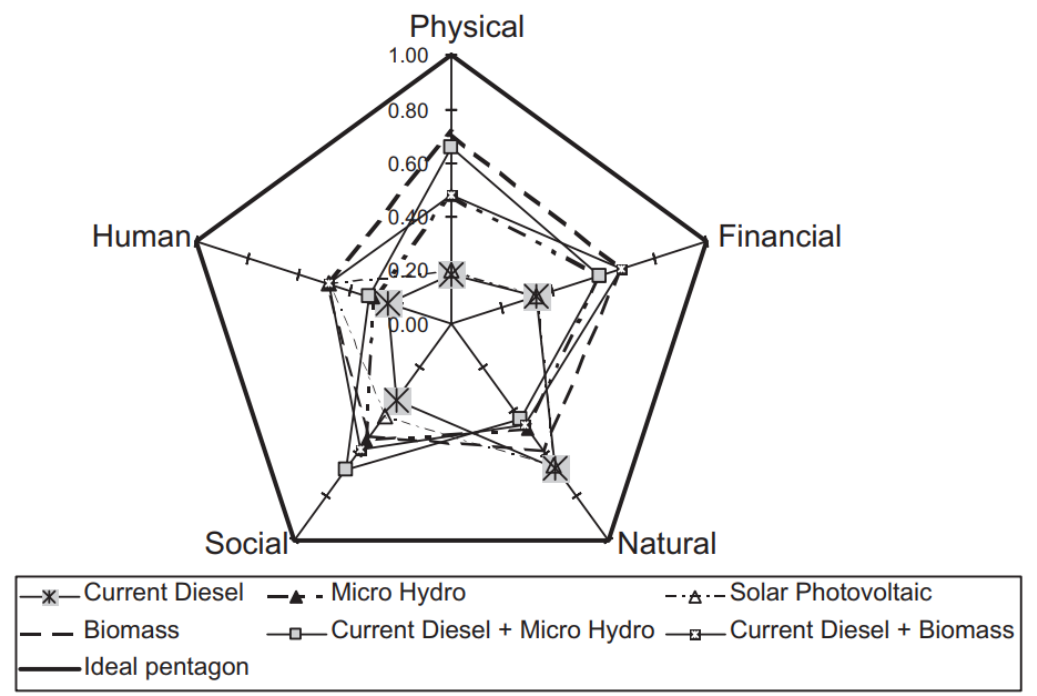

Figure 5: Impact of different technologies regarding five criteria, using SURE-DSS (Henao et al., 2012)

Keller et al. (2007) develop the OptElDec simulation tool which has flexibility to be used in different contexts and its structure in two phases: an optimisation and a multicriteria process. So, first several scenarios are generated sizing the generators for different generation technology combinations in order to cover diverse energy usages. Then, the AHP technique is used to select the best scenario, considering the opinion of all stakeholders involved, distinguishing between quantitative (energy cost, unmet demand, etc.) and qualitative (social acceptance, visual impact, etc.) criteria. However, a single technology may be installed at each generation point and the distribution scheme is not analysed (a single microgrid is considered without defining its structure).

Finally, a comprehensive methodology has been proposed by the authors of this paper (Domenech et al., 2015b), to guide project developers across the design of wind-PV-battery stand-alone electrification projects in rural communities of developing countries. Although not a public software, the methodology is included given its flexibility to be adapted to different contexts. Figure 6 shows the scheme of the methodology. Some assessments are initially 
carried out to gather information about the socioeconomic characteristics of the target community and its population, the wind and solar resources, and the equipment available in the region. Then, the design process is performed in three decision levels, ordered according to the importance of the decisions taken (Thery \& Zarate, 2009). At the three levels, the cost is minimised since it is an important limitation in rural areas of developing countries. In addition, at the first level, the energy usages covered are analysed to satisfy real end-user demand requirements. At the second level, the configuration of the electrical distribution is examined to ease the way as the electrification project is managed. At the third level, the typology of equipment installed is studied to improve the security of supply. As shown in Figure 6, each decision level is divided in two steps. First, a set of electrification options is generated using a mathematical model developed by the same set of authors (Ferrer-Martí et al., 2013; Domenech et al., 2015a). Then, the most appropriate option is selected based on economical, technical and social criteria, using the compromise programming multicriteria technique (Domenech et al., $2015 b$ ). The whole process is complemented by an iterative procedure to test many design options while progressing in-depth into the problem, depending on the results obtained so far. As a result, the minimum cost, size and location of the equipment to install is obtained, as well as the individual supplies, the microgrids and their structure.

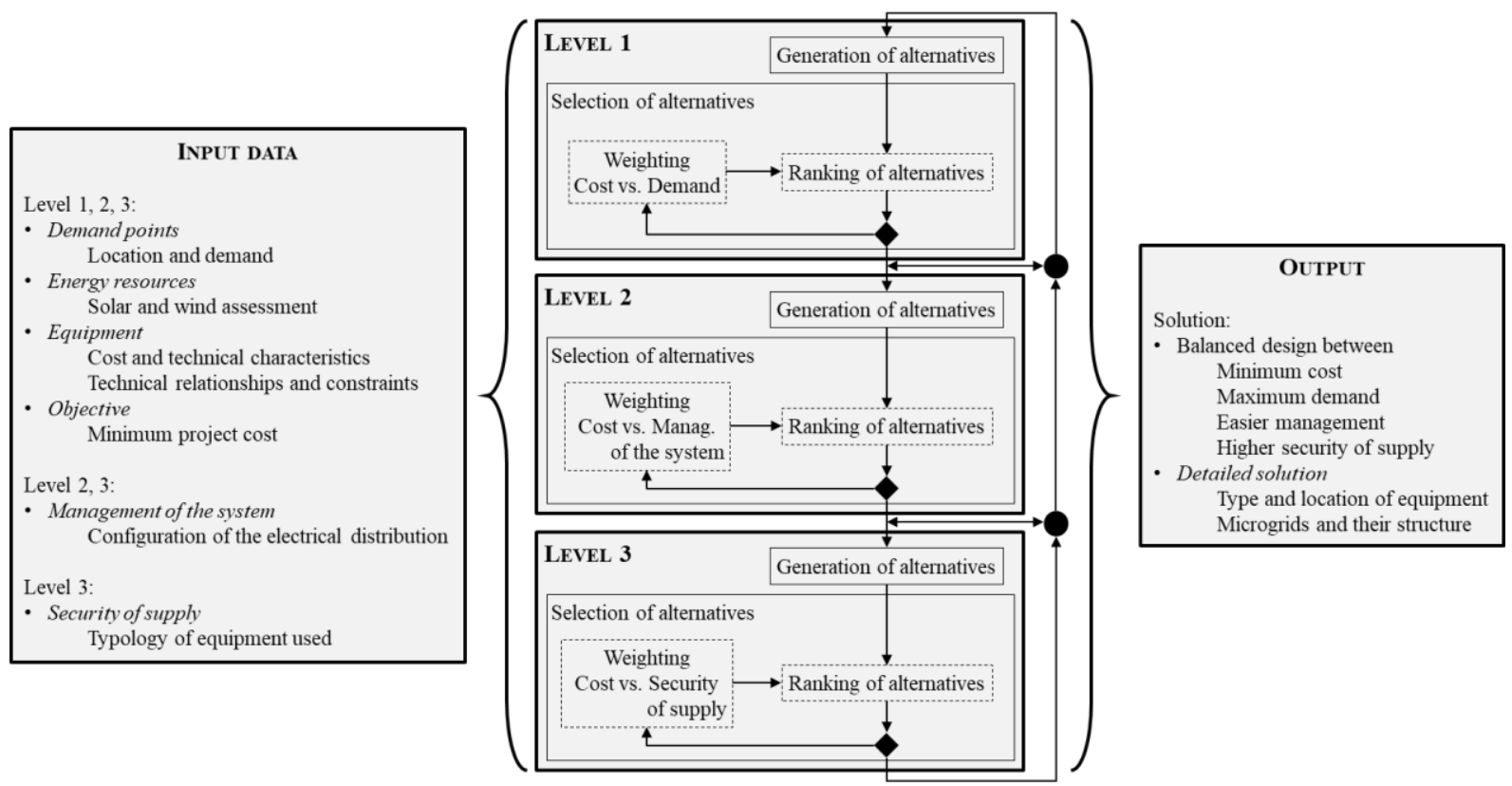

Figure 6: Methodology to design wind-PV stand-alone electrification projects combining microgrids and individual supplies (adapted from Domenech et al., 2015b)

\section{Main findings and discussion}

From the literature review, it can be concluded that optimisation models can be classified into two main categories. On the one hand, models focussing on the minimum cost sizing of a generation system in order to satisfy the specified demand, according to the energy resources. A great detail in the equipment to be installed is considered, through an hourly analysis over a year to ensure the appropriate dimension of generators. Consequently, this approach is suitable when the assessment of the energy demand and resources has been carried out in a deeply 
manner and a certainty context, as the suitability of the solution is inevitable linked to the quality in the estimation of such values. This means having appropriate equipment to measure the wind and solar resources in the target area, and suitable tools to gather information about electricity consumption of end-users. Considering that population is moving from traditional energy sources into electricity, this task may be challenging (Gómez-García \& Bartolomé, 2010).

On the other hand, the above models do not examine the way as electricity is shifted from generators to end-users, assuming a unique microgrid scheme. Consequently, several optimisation models analyse the electrical issues along electrical lines to ensure the appropriate performance of microgrids, maximising supply quality or minimising energy losses. Very few models study the combination of microgrids, at concentrations of demand points, and individual supplies, for farther houses. These models allow addressing a common characteristic of rural villages in developing countries, where there is a group of houses with some houses and the main buildings (as school, church, health centre, etc.) and scattered points for farmers (Rojas-Zerpa, 2012). In global terms, optimisation models allow designing suitable electrification solutions from a techno-economic perspective. However, social issues are still an issue, as their modelling is not generally feasible because they respond to end-user preferences rather than specific design characteristics.

Alternatively, multicriteria processes have been used to assist project developers across decision-making. This approach allows taking into account several criteria simultaneously, quantifying the qualitative preferences for some criteria or characteristics in the electrification solution, even considering feasibility thresholds. In addition, instead of obtaining a unique result from a set of input data, many design options can be examined, so the final solution is less subject to the quality of information gathered; which may be very useful in rural areas of developing countries (Alfaro et al., 2017). Multicriteria is a research area still under development so most reviewed works focus on the decision-making process itself, without any detailed examination about the evaluated scenarios or solutions. In addition, their application is mainly centred at large-scale projects, analysing global and macro-economic indicators and electrification solutions; while their application to a local context in developing countries still needs to be addressed, including the specific characteristics of each case study. This lack is probably due to the tight budgets in this context that force projects to be rapidly implemented, rather than progressively adapting the design to the population particularities.

In terms of systematised software, several applications have been developed, which allow project developers to design electrification systems under a user-friendly interface and in such a way that different contexts and situations can be addressed. Software based on optimisation and multicriteria have been developed; in the first case to achieve optimal solutions and in the second case to assess decision-making. Some of the reviewed tools include a sensitivity analysis, to determine the influence of input data on the obtained results. A particular emphasis is put on a few tools using a hybrid approach, i.e. optimisation and multicriteria techniques, which has proved adequate to take advantage of the strengths of each other (Bhattacharyya, 2012). In regions where data gathering is not easy, first developing efficient solutions, through 
optimisation models, and then selecting the best one, through multicriteria processes, has been recommended to achieve a higher realism in representing the problem and taking decisions knowing part of the problem beforehand (Alarcón-Rodríguez et al., 2010). As a summary of the most relevant design-aid tools (HOMER, ViPOR, SURE and Domenech et al. 2015), Table 1 shows the characteristics of the problem that can be addressed with each one, in terms of electricity supply (wind and PV generation, battery storage and diesel backup), electricity distribution (microgrids and individual supplies), design considerations (economic, technical, environmental and social issues) and a sensitivity analysis of results.

The research on the design of wind-PV rural electrification projects is still under development. Over the last years, several initiatives are reviewing implemented projects in different contexts, aiming to identify their strengths and limitations (Ilskog, 2008; Brent \& Rogers, 2010; FerrerMartí et al., 2012; Lillo et al., 2015a; López-González et al., 2017). In this regard, the approaches used to assist project developers across the design process should be able to incorporate the novel issues identified from the assessment of real projects. This is the key issue when extending the existing approaches or when developing new ones; particularly those systematising the design process.

Table 1: Comparison of the main characteristics of the problem to be addressed using the most relevant tools to design electrification systems in remote areas of developing countries

\begin{tabular}{|l|c|c|c|c|}
\hline \multicolumn{1}{|c|}{ Characteristic } & $\begin{array}{c}\text { HOMER } \\
\text { (Lal et al. } \\
\mathbf{2 0 1 1})\end{array}$ & $\begin{array}{c}\text { ViPOR } \\
\text { (Lambert and } \\
\text { Hittle 2000) }\end{array}$ & $\begin{array}{c}\text { SURE } \\
\text { (Henao et } \\
\text { al. 2012) }\end{array}$ & $\begin{array}{c}\text { Methodology } \\
\text { (Domenech } \\
\text { et al. 2015a) }\end{array}$ \\
\hline Wind generation & $\mathrm{X}$ & & $\mathrm{X}$ & $\mathrm{X}$ \\
\hline PV generation & $\mathrm{X}$ & & $\mathrm{X}$ & $\mathrm{X}$ \\
\hline Battery storage & $\mathrm{X}$ & & & $\mathrm{X}$ \\
\hline Diesel backup & $\mathrm{X}$ & & & $\mathrm{X}$ \\
\hline $\begin{array}{c}\text { Microgrid distribution } \\
\text { several microgrids }\end{array}$ & & $\mathrm{X}$ & $\mathrm{X}$ \\
\hline Individual distribution & & $\mathrm{X}$ & $\mathrm{X}$ & $\mathrm{X}$ \\
\hline Economic issues & $\mathrm{X}$ & $\mathrm{X}$ & $\mathrm{X}$ & $\mathrm{X}$ \\
\hline Technical issues & $\mathrm{X}$ & $\mathrm{X}$ & $\mathrm{X}$ & $\mathrm{X}$ \\
\hline Environmental issues & $\mathrm{X}$ & & & \\
\hline Social issues & & $\mathrm{X}$ & & \\
\hline Sensitivity analysis & $\mathrm{X}$ & & \\
\hline
\end{tabular}

\section{Conclusion}

Lack of electricity access is still an issue in many isolated and poor rural communities in developing countries, where the techno-economic resources are generally limited for an appropriate analysis of electrification solutions. This paper is particularly focussed on electrification projects combining wind-PV generation technologies, as they do not create external dependencies and are present almost everywhere; storing electricity in batteries, to mismatch the gap between generation and consumption periods; and distributing electricity through microgrids and individual supplies. The design of such projects may be seen as a complex combinatorial optimisation problem, even more when including social issues in order to satisfy end-users real requirements and expectations. 
In order to assist in the decision-making process when designing electrification projects, different approaches and methods have been developed. The literature review is organised in three main categories: optimisation processes, multicriteria processes and software tools. The first category aims to optimise an objective function (generally the project cost) subject to a set of technical constraints, using exact or heuristic algorithms for the resolution. Some works focus on the generation system, by optimising the combination of technologies in order to cover the specified demand, according to the available resources. Other works, focus on the distribution system by designing detailed microgrids, which may not be appropriate in regions where reliability is not as relevant as providing a basic electricity service at a limited budget. Very few works simultaneously address the design of the generation and distribution systems in order to entirely define electrification projects, but without including social aspects. The second category starts from a set of predefined scenarios and selects the best one according to several criteria, commonly grouped into technical, economic, social and environmental. The reviewed works tend to address the decision-making procedure, but the way as the predefined solutions are obtained is not always detailed. In any case, the decision-making procedure is generally structured in four steps: criteria definition, criteria weighting, alternatives evaluation and results aggregation. Different multicriteria techniques can be used along this process, although their application to rural areas of developing countries, particularly regarding the design of electrification projects, has not been much studied. Finally, the third category compiles software tools developed under user-friendly interface to be easily spread among project developers. Different options have been proposed to assist in the design of the generation and, in a lesser amount, the distribution system. However, their application to rural areas in developing countries is limited given the lack of social aspects into the analysis and interactive interfaces enabling decisions to be progressively taken while studying the problem. Hence, although the technical issues may be achieved, the project sustainability is not ensured as end-users get the solution decided by project developers, without getting involved into the design process. Table 2 summarises the main strengths and limitations of the three reviewed approaches, which could be considered by researchers and practitioners when addressing the design of wind-PV electrification projects for remote villages of developing countries.

In short, optimisation processes focus on sizing generation technologies to satisfy the demand according to the energy resources or electrical details of distribution microgrids. The simultaneous design of generation and distribution solutions has been less studied, and social aspects are conceived as technical constraints having a social benefit. Multicriteria processes start from a set of predefined scenarios and select the best one/s according to technical, economic, social and environmental criteria. Attention is put on decision-making, but not the definition of the predefined scenarios. Finally, systematised tools provide user-friendly interfaces to be spread among project developers in developing countries. Social issues are receiving increased attention, particularly when addressing very specific issues at a local scale. 
Table 2: Strengths and limitations of the approaches reviewed to design electrification projects in remote areas of developing countries

\begin{tabular}{|c|c|c|}
\hline Approach & Strengths & Limitations \\
\hline $\begin{array}{c}\text { Optimisation } \\
\text { Processes }\end{array}$ & $\begin{array}{l}\text { - Allow size and locate equipment with as } \\
\text { much detail as required, combining } \\
\text { generation and distribution technologies } \\
\text { - Can be developed according to the } \\
\text { particular characteristics of each case } \\
\text { study }\end{array}$ & $\begin{array}{l}\text { - Usually based on complex mathematical } \\
\text { formulae and programming, limiting their } \\
\text { usefulness for some decision-makers } \\
\text { - Limited to a unique objective function, } \\
\text { not generally considering social issues }\end{array}$ \\
\hline $\begin{array}{c}\text { Multicriteria } \\
\text { Processes }\end{array}$ & $\begin{array}{l}\text { - Facilitate selection among alternatives, } \\
\text { based on several criteria, to choose } \\
\text { balanced solutions } \\
\text { - Allow simultaneously considering } \\
\text { quantitative and qualitative aspects }\end{array}$ & $\begin{array}{l}\text { - Require from previous definition of } \\
\text { alternatives, which might not be } \\
\text { straightforward } \\
\text { - Subjectivities of decision-makers can } \\
\text { have a high influence on results }\end{array}$ \\
\hline $\begin{array}{c}\text { Systematised } \\
\text { Tools }\end{array}$ & $\begin{array}{l}\text { - Provide user-friendly interface, including } \\
\text { visual details of solutions, not requiring } \\
\text { high expertise of decision-makers } \\
\text { - Allow easily testing several options, } \\
\text { iteratively or by trial and error, in order } \\
\text { to go in depth into the problem }\end{array}$ & $\begin{array}{l}\text { - Do not always allow to consider the } \\
\text { specific characteristics of each case study } \\
\text { - Open source licenses are not always } \\
\text { available, limiting their usability in low- } \\
\text { economy regions }\end{array}$ \\
\hline
\end{tabular}

\section{Acknowledgments}

This project is the result of a large research which has been funded mainly by was funded by the Spanish Ministry of Science and Innovation (project ENE2015-67253-R) and the Centre for Cooperation Development (CCD) of the Universitat Politècnica de Catalunya (UPC). The authors are very grateful to the many institutions involved across the investigations; and particularly Intermediate Technology Development Group - Practical Action (Peru), Engineering Without Borders (Spain) and the University College Dublin (UCD). The authors would like to thank the anonymous reviewers in providing comments and suggestions that have helped to improve the paper quality.

\section{References}

1. Abdul-Salam Y, Phimister E. How effective are heuristic solutions for electricity planning in developing countries. Socio-Economic Planning Sciences 55 (2016) 14-24.

2. Afgan NH, Carvalho MG, Hovanov NV. Energy system assessment with sustainability indicators. Energy Policy 28 (2000) 603-612.

3. Ahlborg H, Hammar L. Drivers and barriers to rural electrification in Tanzania and Mozambique - gridextensions, off-grid, and renewable energy technologies. Renewable Energy 61 (2014) 117-124.

4. Akikur RK, Saidur R, Ping HW, Ullah KR. Comparative study of stand-alone and hybrid solar energy systems suitable for off-grid rural electrification: a review. Renewable and Sustainable Energy Reviews 27 (2013) 738-752.

5. Aklin M, Bayer P, Harish SP, Urpelainen J. Does basic energy access generate socioeconomic benefits? A field experiment with off-grid solar power in India. Science Advances 3 (2017) e1602153.

6. Akorede MF, Hizam H, Pouresmaeil E. Distributed energy resources and benefits to the environment. Renewable and Sustainable Energy Reviews 14 (2010) 724-734.

7. Alarcón-Rodriguez A, Ault G, Galloway S. Multi-objective planning of distributed energy resources: A review of the state-of-the-art. Renewable and Sustainable Energy Reviews 14 (2010) 1353-1366.

8. Alfaro JF, Miller S, Johnson JX, Riolo RR. Improving rural electricity system planning: an agent-based model for stakeholder engagement and decision making. Energy Policy 101 (2017) 317-331.

9. Alkarrami F, Iqbal T, Pope K. Optimal sizing of a stand-alone hybrid energy system for water pumping in Sirte, Libya. IEEE Electrical Power and Energy Conference (2016) 1-5. ISBN: 978-1-5090-1919-9/16.

10. Alvial-Palavicino C, Garrido-Echeverría N, Jiménez-Estévez G, Reyes L, Palma-Behnke R. A methodology for community engagement in the introduction of renewable based smart microgrid. Energy for Sustainable Development 15 (2011) 314-323. 
11. Alzola JA, Vechiu I, Camblong H, Santos M, Sall, Sowd G. Microgrids project, Part 2: Design of an electrification kit with high content of renewable energy sources in Senegal. Renewable Energy 34 (2009) 2151-2159.

12. Aoki K, Nara K, Satoh T, Kitagawa M, Yamanaka K. New approximate optimization method for distribution system planning. IEEE Transactions on Power Systems 5 (1990).

13. Ashok S. Optimized model for community-based hybrid energy system. Renewable Energy 32 (2007) 1155-1164.

14. Atamtürk A, Savelsbergh MWP. Integer-programming software systems. Annals of Operations Research 140 (2005) 67-124.

15. Bahramara S, Moghaddam MP, Haghifam MR. Optimal planning of hybrid renewable energy systems using HOMER: a review. Renewable and Sustainable Energy Reviews 62 (2016) 609-620.

16. Bala BK, Siddique SA. Optimal design of a PV-diesel hybrid system for electrification of an isolated island-Sandwip in Bangladesh using genetic algorithm. Energy for Sustainable Development 13 (2009) 137-142.

17. Baldwin E, Brass JN, Carley S, Maclean LM. Electrification and rural development: issues of scale in distributed generation. WIRES Energy and Environment 4(2) (2015) 196-211.

18. Baños R, Manzano-Agugliaro F, Montoya FG, Gil C, Alcayde A, Gómez J. Optimization methods applied to renewable and sustainable energy: a review. Renewable and Sustainable Energy Reviews 15 (2011) 1753-1766.

19. Barley CD, Lew DJ, Flowers LT. Sizing wind/photovoltaic hybrids for households in Inner Mongolia. National Renewable Energy Laboratory - Technical Report DO059620 (1997).

20. Bekele G, Tadesse G. Feasibility study of small hydro/PV/wind hybrid system for off-grid rural electrification in Ethiopia. Applied Energy 97 (2012) 5-15.

21. Belouda M, Jaafar A, Sareni B, Roboam X, Behadj J. Integrated optimal design and sensitivity analysis of a stand alone wind turbine system with storage for rural electrification. Renewable and Sustainable Energy Reviews 28 (2013) 616-624.

22. Biswas WK, Bryce P, Diesendorf M. Model for empowering rural poor through renewable energy technologies in Bangladesh. Environmental Science \& Policy 4 (2001) 333-344.

23. Bhattacharyya SC. Review of alternative methodologies for analyzing off-grid electricity supply. Renewable and Sustainable Energy Reviews 16 (2012) 677- 694.

24. Brans JP, Vincke P, Mareschal B. How to select and how to rank projects: the PROMETHEE method. European Journal of Operational Research 24 (1986) 228-238.

25. Brent AC, Kruger WJL. Systems analyses and the sustainable transfer of renewable energy technologies: a focus on remote areas of Africa. Renewable Energy 34(7) (2009) 1774-1781.

26. Brent AC, Rogers DE. Renewable rural electrification: sustainability assessment of mini-hybrid off-grid technological systems in the African context. Renewable Energy 35 (2010) 257-265.

27. Brivio C, Moncecchi M, Mandelli S, Merlo M. A novel software package for the robust design of off-grid power systems. Journal of Cleaner Production 166 (2017) 668-679.

28. Browne D, O’Regan B, Moles R. Use of multi-criteria analysis to explore alternative domestic energy and electricity policy scenarios in an Irish city-region. Energy 35 (2010) 518-528.

29. Bogno B, Sali M, Alliere M. Technical and economic sizing of the energy storage in an autonomous hybrid power generator for rural electrification in sub-equatorial area of Africa. Energy Procedia 74 (2015) 707-717.

30. Carrasco LM, Narvarte L, Lorenzo E. Operational costs of a 13,000 solar home systems rural electrification programme. Renewable and Sustainable Energy Reviews 20 (2013) 1-7.

31. Cavallaro F, Ciraolo L. A multicriteria approach to evaluate wind energy plants on an Italian island. Energy Policy 33 (2005) 235-244.

32. Chatzimouratidis AI, Pilavachi PA. Technological, economic and sustainability evaluation of power plants using the Analytic Hierarchy Process. Energy Policy 37 (2009) 778-787.

33. Chauhan A, Saini RP. Discrete harmony search based size optimization of integrated renewable energy system for remote rural areas of Uttarakhand state in India. Renewable Energy 94 (2016) 587-604. 
34. Chaurey A, Kandpal TC. Assessment and evaluation of PV based decentralized rural electrification: an overview. Renewable and Sustainable Energy Reviews 14(8) (2010a) 2266-2278.

35. Chaurey A, Kandpal TC. A techno-economic comparison of rural electrification based on solar home systems and PV microgrids. Energy Policy 38 (2010b) 3118-3129.

36. Cherni JA, Dyner I, Henao F, Jaramillo P, Smith R, Olade R. Energy supply for sustainable rural livelihoods. A multi-criteria decision-support system. Energy Policy 35 (2007) 1493-1504.

37. Cherni JA, Font RO, Serrano L, Henao F, Urbina A. Systematic assessment of carbon emissions from renewable energy access to improve rural livelihoods. Energies 9(12) (2016) 1-19.

38. Connolly D, Lund H, Mathiesen BV, Leahy M. A review of computer tools for analysing the integration of renewable energy into various energy systems. Applied Energy 87(4) (2010) 1059-1082.

39. Colombo E, Romer F, Mattarolo L, Barbieri J, Morazzo M. An impact evaluation framework based on sustainable livelihoods for energy development projects: an application to Ethiopia. Energy Research \& Social Science 39 (2018) 78-92.

40. DFID. Energy for the poor - underpinning the millennium development goals. Department of International Development (2002).

41. Díaz P, Arias CA, Gómez-González M, Sandoval D, Lobato R. Solar home system electrification in dispersed rural areas: a 10-year experience in Jujuy, Argentina. Progress in Photovoltaics: Research and Applications 21(3) (2013) 297-307.

42. Domenech B, Ferrer-Martí L, Lillo P, Pastor R, Chiroque J. A community electrification project: combination of microgrids and household systems fed by wind, PV or micro-hydro energies according to micro-scale resource evaluation and social constraints. Energy for Sustainable Development 23 (2014) 275-285.

43. Domenech B, Ferrer-Martí L, Pastor R. Including management and security of supply constraints for designing stand-alone electrification systems in developing countries. Renewable Energy 80 (2015a) 359-369.

44. Domenech B, Ferrer-Martí L, Pastor R. Hierarchical methodology to optimize the design of stand-alone electrification systems for rural communities considering technical and social criteria. Renewable and Sustainable Energy Reviews 51 (2015b) 182-196.

45. Dorji T, Urmee T, Jennings P. Options for off-grid electrification in the Kingdom of Bhutan. Renewable Energy 45 (2012) 51-58.

46. Dufo-López R, Bernal-Agustín JL. HOGA (Hybrid Optimization by Genetic Algorithms) software. Disponible en www.unizar.es/rdufo (2011).

47. Dufo-López R, Bernal-Agustín JL, Yusta-Loyo JM, Domínguez-Navarro JA, Ramírez-Rosado IJ, Lujano J, Aso I. Multi-objective optimization minimizing cost and life cycle emissions of stand-alone PV-winddiesel systems with batteries storage. Applied Energy 88 (2011) 4033-4041.

48. Edwards W. How to use multiattribute utility measurement for social decision making. IEEE Transactions on Systems Man and Cybernetics 7 (1977) 326-340.

49. Ekren BY, Ekren O. Simulation based size optimization of a PV/wind hybrid energy conversion system with battery storage under various load and auxiliary energy conditions. Applied Energy 86 (2009) 13871394.

50. Elma E, Selamogullari US. A comparative sizing analysis of a renewable energy supplied stand-alone house considering both demand side and source side dynamics. Applied Energy 96 (2012) 400-408.

51. Eppel T. Description and procedure invariance in multiattribute utility measurement. School of Management, Purdue Univ., West Lafayette, IN, (1992).

52. Escobar R, Vilar D, Velo E, Ferrer-Martí L, Domenech B. Promoting and improving renewable energy projects through local capacity development. Modeling and optimization of renewable energy systems, Ed. Intech (2012).

53. ESMAP. Technical and economic assessment of off-grid, mini-grid and grid electrification technologies. Energy Sector Management Assistance Program, technical paper (2007).

54. Fadaeenejad M, Radzi MAM, AbKadir MZA, Hizam H. Assessment of hybrid renewable power sources for rural electrification in Malaysia. Renewable and Sustainable Energy Reviews 30 (2014) 299-305. 
55. Ferrer-Martí L, Garwood A, Chiroque J, Escobar R, Coello J, Castro M. A community small-scale wind generation project in Peru. Wind Engineering. Special Issue on Small Wind Energy for Developing Countries (2010) 277-288.

56. Ferrer-Martí L, Pastor R, Capó GM, Velo E. Optimizing microwind rural electrification projects. A case study in Peru. Journal of Global Optimization 50 (2011) 127-143.

57. Ferrer-Martí L, Garwood A, Chiroque J, Ramírez B, Marcelo O, Garfí M, Velo E. Evaluating and comparing three community small-scale wind electrification projects. Renewable \& Sustainable Energy Reviews 16 (2012) 5379-5390.

58. Ferrer-Martí L, Domenech B, García-Villoria A, Pastor R. A MILP model to design hybrid windphotovoltaic isolated rural electrification projects in developing countries. European Journal of Operational Research 226(2) (2013) 293-300.

59. Fomin FV, Kratsch D. Exact exponential algorithms. Springer Heidelberg Dordrech London New York (2010).

60. Gandini D, de Almeida AT. Direct current microgrids based on solar power systems and storage optimization as a tool for cost-effective rural electrification. Renewable Energy 111 (2017) 275-283.

61. Georgopoulou E, Lalas D, Papagiannakis L. A Multicriteria Decision aid approach for energy planning problems: The case of renewable energy option. European Journal of Operational Research 103 (1997) 3854.

62. Gheiratmand A, Effatnejad R, Hedayati M. Technical and economic evaluation of hybrid wind/PV/battery systems for off-grid areas using HOMER software. International Journal of Power Electronics and Drive System 7 (2016) 134-143.

63. GIZ. Tools for mini-grid practitioners. German International Cooperation (2016). Available at: https://cleanenergysolutions.org/training/tools-facilitate-mini-grid-deployment. Last access: 29/10/2017.

64. Gonen T, Foote BL. Distribution-system planning using mixed-integer programming. IEEE Proceedings 128C (1981).

65. Greening LA, Bernow S. Design of coordinated energy and environmental policies: use of multi-criteria decision-making. Energy Policy 32 (2004) 721-735.

66. Grimm M, Munyehirwe A, Peters J, Sievert M. A first step up the energy ladder? Low cost solar kits and household's welfare in rural Rwanda. IZA Discussion Papers (2014) No. 8594.

67. Gómez-García V, Bartolomé MM. Rural electrification systems based on renewable energy: the social dimensions of an innovative technology. Technology in Society 32(4) (2010) 303-311.

68. Gupta A, Saini RP, Sharma MP. Modeling of hybrid energy system Part I: Problem formulation and model development. Renewable Energy 36 (2011) 459-465.

69. Henao F, Cherni JA, Jaramillo P, Dyner I. A multicriteria approach to sustainable energy supply for the rural poor. European Journal of Operational Research 218 (2012) 801-809.

70. Hiremath RB, Shikha S, Ravindranath NH. Decentralized energy planning, modeling and application: a review. Renewable and Sustainable Energy Reviews 11 (2007) 729-752.

71. Hong GW, Abe N. Sustainability assessment of renewable energy projects for off-grid rural electrification: The Pangan-an Island case in the Philippines. Renewable and Sustainable Energy Reviews 16 (2012) 54-64.

72. Honghua X, Barley CD, Tu P. The optimization design for $4 \mathrm{~kW}$ wind/PV hybrid generating system in Tibet. Acta Energiae Solaris Sinica (1998).

73. Hosseinalizadeh R, Rafiei E sadat, Alavijeh AS, Ghaderi SF. Economic analysis of small wind turbines in residential energy sector in Iran. Sustainable Energy Technologies and Assessments 20 (2017) 58-71.

74. IEA. World energy outlook. International Energy Agency (2017).

75. Ilskog E. Indicators for assessment of rural electrification - An approach for the comparison of apples and pears. Energy Policy 36(7) (2008) 2665-2673.

76. Jebaraj S, Iniyanb S. A review of energy models. Renewable and Sustainable Energy Reviews 10 (2006) 281-311.

77. Kaldellis JK, Kavadias KA, Koronakis PS. Comparing wind and photovoltaic stand-alone power systems used for the electrification of remote consumers. Renewable and Sustainable Energy Reviews 11 (2007) $57-77$. 
78. Kaldellis JK, Zafirakis D. Optimum sizing of stand-alone wind-photovoltaic hybrid systems for representative wind and solar potential cases of the Greek territory. Journal of Wind Engineering and Industrial Aerodynamics 107-108 (2012) 169-178.

79. Kanase-Patil AB, Saini RP, Sharma MP. Integrated renewable energy systems for off-grid rural electrification of remote area. Renewable Energy 35(6) (2010) 1342-1349.

80. Karger CR, Hennings W. Sustainability evaluation of decentralized generation. Renewable and Sustainable Energy Reviews 13 (2009) 583-593.

81. Karumba M, Muchapondwa E. The impact of micro hydroelectricity on household welfare indicators. Economic Research Southern Africa (2017) WP659.

82. Kaundinya DP, Balachandra P, Ravindranath NH. Grid-connected versus stand-alone energy systems for decentralized power - a review of literature. Renewable and Sustainable Energy Reviews 13(8) (2009) 2041-2050.

83. Keeney RL, Raiffa H. Decisions with multiple objectives: preferences and value tradeoffs. New York, Wiley (1976).

84. Keller S, Naciri S, Nejmi A, Dos Ghali J. Simulation-based decision support tool for electrification of isolated areas using a network with multiple renewable sources. International Conference on Clean Electrical Power (2007).

85. Kemausuor F, Ackom E. Toward universal electrification in Ghana. WIRES Energy and Environment 6(1) (2017) 1-14.

86. Kirubi C, Jacobson A, Kammen DM, Mills A. Community-based electric micro-grids can contribute to rural development: evidence from Kenya. World Development 37 (2009) 1208-1221.

87. Khare V, Nema S, Baredar P. Solar-wind hybrid renewable energy systems: a review. Renewable and Sustainable Energy Reviews 58 (2016) 23-33.

88. Khatib T, Mohamed A, Sopian K. Optimization of a PV/wind micro-grid for rural housing electrification using a hybrid iterative/genetic algorithm: case study of Kuala Terengganu, Malaysia. Energy and Buildings 47 (2012) 321-331.

89. Klamler C. On the closeness aspect of three voting rules: Borda - Copeland - Maximin. Group Decision and Negotiation 14 (2005) 233-240.

90. Kumar MVM, Banerjee R. Analysis of isolated power systems for village electrification. Energy for Sustainable Development 14(3) (2010) 213-222.

91. Lal DK, Dash BB, Akella AK. Optimization of PV/Wind/Micro-Hydro/Diesel Hybrid Power System in HOMER for the Study Area. International Journal on Electrical Engineering and Informatics 3 (2011) 307 325.

92. Lambert TW, Hittle DC. Optimization of autonomous village electrification systems by simulated annealing. Solar Energy, 68 (2000) 121-132.

93. Leary J, While A, Howell R. Locally manufactured wind power technology for sustainable rural electrification. Energy Policy 43 (2012) 173-183.

94. Lemaire X. Off-grid electrification with solar home systems: the experience of a fee-for-service concession in South Africa. Energy for Sustainable Development 15(3) (2011) 277-283.

95. Li C, Ge X, Zheng Y, Xu C, Ren Y, Song C, Yang C. Techno-economic feasibility study of autonomous hybrid wind/PV/battery power system for a household in Urumqi, China. Energy 55(15) (2013) 263-272.

96. Lillo P, Ferrer-Martí L, Boni A, Fernández-Baldor A. Assessing management models for off-grid renewable energy electrification projects using the Human Development approach: case study in Peru. Energy for Sustainable Development 25 (2015a) 17-26.

97. Lillo P, Ferrer-Martí L, Fernández-Baldor A, Boni A. A new integral management model and evaluation method to enhance sustainability of renewable energy projects for energy and sanitation services. Energy for Sustainable Development 29 (2015b) 1-12.

98. Loken E. Use of multicriteria decision analysis methods for energy planning problems. Renewable and Sustainable Energy Reviews 11 (2007) 1584-1595.

99. López-González A, Domenech B, Gómez-Hernández D, Ferrer-Martí L. Renewable microgrid projects for autonomous small-scale electrification in Andean countries. Renewable and Sustainable Energy Reviews 79 (2017) 1255-1265. 
100. Lukuyu JM, Cardell JB. Hybrid power system options for off-grid rural electrification in Northern Kenya. Smart Grid and Renewable Energy 5 (2014) 89-106.

101. Mahapatra S, Dasappa S. Rural electrification: optimising the choice between decentralised renewable energy sources and grid extension. Energy for Sustainable Development 16(2) (2012) 146-154.

102. Mandelli S, Barbieri J, Mereu R, Colombo E. Off-grid systems for rural electrification in developing countries: definitions, classification and a comprehensive literature review. Renewable and Sustainable Energy Reviews 58 (2016a) 1621-1646.

103. Mandelli S, Brivio C, Colombo E, Merlo M. A sizing methodology based on levelized cost of supplied and lost energy for off-grid rural electrification systems. Renewable Energy 89 (2016b) 475-488.

104. Mandelli S, Brivio C, Colombo E, Merlo M. Effect of load profile uncertainty on the optimum sizing of off-grid PV systems for rural electrification. Sustainable Energy Technologies and Assessments 18 (2016c) 34-47.

105. Manwell JF, Rogers A, Hayman G, Avelar CT, McGowan JG, Abdulwahid U, Wu K. HYBRID2 - A hybrid system simulation model. Theory manual. Renewable Energy Research Laboratory (2006).

106. Mendes G, Ioakimidis C, Ferrao P. On the planning and analysis of integrated community energy systems: A review and survey of available tools. Renewable and Sustainable Energy Reviews 15 (2011) 4836- 4854.

107. Mostofi F, Shayeghi H. Feasibility and optimal reliable design of renewable hybrid energy system for rural electrification in Iran. International Journal of Renewable Energy Research 2(4) (2012) 574-582.

108. Müggenburg H, Tillmans A, Schweizer-Reis P, Raabe T, Adelmann P. Social acceptance of PicoPV systems as a means of rural electrification - a socio-technical case study in Ethiopia. Energy for Sustainable Development 16 (2012) 90-97.

109. Nandi SK, Ghosh HR. Prospect of wind-PV-battery hybrid power system as an alternative to grid extension in Bangladesh. Energy 35(7) (2010) 3040-3047.

110. Nässen J, Evertsson J, Andresson BA. Distributed power generation versus grid extension: an assessment of solar photovoltaics for rural electrification in Northern Ghana. Progress in Photovoltaics: Research and Applications 10 (2002) 495-510.

111. Nema P, Nema RK, Rangnekar S. A current and future state of art development of hybrid energy system using wind and PV-solar: a review. Renewable and Sustainable Energy Reviews 13(8) (2009) 2096-2103.

112. Neves D, Silva CA, Connors S. Design and implementation of hybrid renewable energy systems on microcommunities: a review on case studies. Renewable and Sustainable Energy Reviews 31 (2014) 935-946.

113. Notton G, Diaf S, Stoyanov L. Hybrid photovoltaic/wind energy systems for remote locations. Energy Procedia 6 (2011) 666-677.

114. Nygaard I, Dafrallah T. Utility led rural electrification in Morocco: combining grid extension, mini-grids, and solar home systems. WIRES Energy and Environment 5(2) (2016) 155-168.

115. Obeng GY, Akuffo FO, Braimah I, Evers HD, Mensah E. Impact of solar photovoltaic lighting on indoor air smoke in off-grid rural Ghana. Energy for Sustainable Development 12 (2008) 59-65.

116. Olatomiwa L, Mekhilef S, Huda ASN, Ohunakin OS. Economic evaluation of hybrid energy systems for rural electrification in six geo-political zones of Nigeria. Renewable Energy 83 (2015) 435-446.

117. Ondraczek J. The sun rises in the east (of Africa): a comparison of the development and status of solar energy markets in Kenya and Tanzania. Energy Policy 56 (2013) 407-417.

118. Ostergaard PA. Reviewing optimization criteria for energy systems analyses of renewable energy integration. Energy 34 (2009) 1236-1245.

119. Paciornik N, Ferland JA, Cleroux R. The electrical distribution network planning problem. International Transaction in Operational Research 10 (2003) 77-87.

120. Palit D. Solar energy programs for rural electrification: experiences and lessons from South Asia. Energy for Sustainable Development 17(3) (2013) 270-279.

121. Pedersen MB. Deconstructing the concept of renewable energy-based mini-grids for rural electrification in East Africa. WIRES Energy and Environment 5(5) (2016) 570-587.

122. Pohekar SD, Ramachandran M. Application of multi-criteria decision making to sustainable energy planning - A review. Renewable and Sustainable Energy Reviews 8 (2004) 365-381.

123. Polatidis H, Haralambopoulos DA, Munda G, Vreeker R. Selecting an appropriate multi-criteria analysis technique for renewable energy planning. Energy Sources 1 (2006) 181-193. 
124. Ponce de Leao MT, Matos MA. Multicriteria distribution network planning using simulated annealing. International Transactions in Operational Research 6 (1999) 377-391.

125. Prakash K, Lallu A, Islam FR, Mamun KA. Review of power system distribution network architecture. $3 \mathrm{dr}$ Asia-Pacidic World Congress on Computer Science and Engineering (2016). ISBN: 978-1-5090-5753-5/16.

126. Rahman MdM, Paatero JV, Lahdelma R. Evaluation of choices for sustainable rural electrification in developing countries: a multicriteria approach. Energy Policy 59 (2013) 589-599.

127. Ranaboldo M, Domenech B, Vilar D, Ferrer-Martí L, Pastor R, García-Villoria A. Renewable energy projects to electrify rural communities in Cape Verde. Applied Energy 118 (2014a) 280-291.

128. Ranaboldo M, García-Villoria A, Ferrer-Martí L, Pastor R. A heuristic method to design autonomous village electrification projects with renewable energies. Energy 73 (2014b) 96-109.

129. Ranaboldo M, Domenech B, Reyes GA, Ferrer-Martí L, Pastor R, García-Villoria A. Off-grid community electrification projects based on wind and solar energies: a case study in Nicaragua. Solar Energy 117 (2015a) 268-281.

130. Ranaboldo M, García-Villoria A, Ferrer-Martí L, Pastor R. A meta-heuristic method to design off-grid community electrification projects with renewable energies. Energy 93(2) (2015b) 2467-2482.

131. Rojas-Zerpa JC. Planificación del suministro eléctrico en áreas rurales de los países en vías de desarrollo: un marco de referencia para la toma de decisiones. Tesis Doctoral, Universidad de Zaragoza (2012).

132. Rojas-Zerpa JC, Yusta JM. Application of multicriteria decision methods for electric supply planning in rural and remote areas. Renewable and Sustainable Energy Reviews 52 (2015) 557-571.

133. Romero C. Teoría de la decisión multicriterio: Conceptos, técnicas y aplicaciones. Ed. Alianza editorial (1993).

134. Rout AK, Parida MK. Design and analysis of SPV-diesel hybrid system for rural electrification in Odisha. International Journal of Scientific \& Engineering Research 4(12) (2013) 129-131.

135. Roy B, Vincke P. Multicriteria analysis: survey and new directions. European Journal of Operational Research 8 (1981) 207-218.

136. Saaty TL. The analytic hierarchy process. Wiley, New York (1980).

137. Sachdev HS, Akella AK. Rural electrification through renewable energy source - small hydro. International Journal of Innovative Research in Engineering Applications 1 (2015) 1-10.

138. Saheb-Koussa D, Haddadi M, Belhamel M. Economic and technical study of a hybrid system (windphotovoltaic-diesel) for rural electrification in Algeria. Applied Energy 86(7-8) (2009) 1024-1030.

139. Samad HA, Khandker SR, Asaduzzaman M, Yunus M. The benefits of solar home systems. An analysis from Bangladesh. The World Bank, Development Research Group, Agriculture and Rural Development Team (2013) WPS6724.

140. San Cristóbal JR. Multi-criteria decision-making in the selection of a renewable energy project in Spain: The VIKOR method. Renewable Energy 36 (2011) 498-502.

141. Schäfer M, Kebir N, Neumann K. Research needs for meeting the challenge of decentralized energy supply in developing countries. Energy for Sustainable Development 15 (2011) 324-329.

142. Shrestha RM, Acharya JS. Sustainable energy access planning - A framework. Mandaluyong City, Philippines: Asian Development Bank (2015).

143. Shyu CW. End-users' experiences with electricity supply from stand-alone mini-grid solar PV power stations in rural areas of western China. Energy for Sustainable Development 17(4) 2013 391-400.

144. Singh G, Baredar P, Singh A, Kurup D. Optimal sizing and location of PV, wind and battery storage for electrification to an island: a case study of Kavaratti, Lakshadweep. Journal of Energy Storage 12 (2017) 78-86.

145. Singh VK, Teja LR, Tiwari J. Direct current alternative current based solar micro-grid in rural energy infrastructure. Fundamentals of Renewable Energy and Application 6 (2015) 1-5.

146. Sinha S, Chandel SS. Review of software tools for hybrid renewable energy systems. Renewable and Sustainable Energy Reviews 32 (2014) 192-205.

147. Soshinskaya M, Crijns-Graus WHJ, Guerrer JM, Vasquez JC. Microgrids: experiences, barriers and success factors. Renewable and Sustainable Energy Reviews 40 (2014) 659-672. 
148. Ter-Gazarian AG, Kagan N. Design model for electrical distribution Systems considering renewable, conventional and energy storage units. IEE Proceedings-C Generation, Transmission and Distribution 139 (1992) 499-504.

149. Thery R, Zarate P. Energy planning: A multi-level and multicriteria decision making structure proposal. CEJOR 17 (2009) 265-274.

150. Trazouei SL, Tarazouei FL, Ghiammy M. Optimal design of a hybrid solar-wind-diesel power system for rural electrification using imperialist competitive algorithm. International Journal of Renewable Energy Research 3(2) (2013) 1-9.

151. Triadó-Aymerich J, Ferrer-Martí L, García-Villoria A, Pastor R. MILP-based heuristics for the design of rural community electrification projects. Computers \& Operations Research 71 (2016) 90-99.

152. Tsilakis A, Tomtsi T, Hatziargyriou ND, Poullikkas A, Malamatenios C, Giakoumelos E, Jaouad OC, Chenak A, Fayek A, Matar T, et al. Review of best practices of solar electricity resources applications in selected Middle East and North Africa (MENA) countries. Renewable and Sustainable Energy Reviews 15(6) (2011) 2838-2849.

153. Turkay, B. Distribution system planning using mixed integer. ELEKTRIK 6 (1998).

154. Ubilla K, Jiménez-Estévez GA, Hernández R, Reyes-Chamorro L, Irigoyen CH, Severino B, PalmaBehnke R. Smart microgrids as a solution for rural electrification: ensuring long-term sustainability through cadastre and business models. IEEE Transactions of Sustainable Energy 5(4) (2014) 1310-1318.

155. UNDP. Human development report. United Nations Development Programme (2015).

156. Urban F, Benders RMJ, Moll HC. Modelling energy systems for developing countries. Energy Policy 35(6) (2007) 3473-3482.

157. Ustun TS, Ozansoy C, Zayegh A. Recent developments in microgrids and example cases around the world - A review. Renewable and Sustainable Energy Reviews 15 (2011) 4030-4041.

158. Wall DL, Thompson GL, Northcote-Green JED. An optimization model for planning radial distribution Networks. IEEF Transactions on Power Apparatus and Systems PAS-98 (1979).

159. Wang J-J, Jing Y-Y, Zhang C-F, Zhao J-H. Review on multi-criteria decision analysis aid in sustainable energy decision-making. Renewable and Sustainable Energy Reviews 13 (2009) 2263-2278.

160. Williams A, Maher P. Mini-grid design for rural electrification: optimization and applications. In: Universitas 21 Energy Conference. Birmingham 8-10 Sept. (2008).

161. Yadoo A, Cruickshank H. The role for low carbon electrification technologies in poverty reduction and climate change strategies: A focus on renewable energy mini-grids with case studies in Nepal, Peru and Kenya. Energy Policy 42 (2012) 591-602.

162. Yang HT, Chen SL. Incorporating a multicriteria decision procedure into the combined dynamic programming/production simulation algorithm for generation expansion planning. IEEE Transactions on Power Systems 4 (1989) 165-175.

163. Zamani MH, Riahy GH. Introducing a new method for optimal sizing of a hybrid (wind/PV/battery) system considering instantaneous wind speed variations. Energy for Sustainable Development 12(2) (2008) 27-33.

164. Zhang X, Gu S, Liu W, Gan L. Wind energy technology development and diffusion: a case study of Inner Mongolia, China. Natural Resources Forum 25 (2001) 33-42.

165. Zhou P, Ang BW, Poh KL. Decision analysis in energy and environmental modeling: An update. Energy 31 (2006) 2604-2622.

166. Zhou W, Lou C, Li Z, Lu L, Yang H. Current status of research on optimum sizing of stand-alone hybrid solar-wind power generation systems. Applied Energy 87 (2010) 380-389.

167. Zubi G, Dufo-López R, Pasaoglu G, Pardo N. Techno-economic assessment of an off-grid PV system for developing regions to provide electricity basic domestic needs: a 2020-2040 scenario. Applied Energy 175 (2016) 309-319. 